\title{
ANALISIS PERBANDINGAN KINERJA PERANGKAT BAHAN BAKAR PLTN TIPE PWR AP 1000 DAN PWR 1000 MWe TIPIKAL DENGAN MENGGUNAKAN PROGRAM KOMPUTER
}

\author{
Arif Nurmawan $^{1)}$, Suroso ${ }^{2)}$ dan Harto Tanujaya ${ }^{1)}$ \\ 1) Program Studi Teknik Mesin, Fakultas Teknik Universitas Tarumanagara, Jakarta \\ ${ }^{2)}$ Pusat Teknologi Reaktor Keselamatan Nuklir - BATAN, Serpong \\ e-mail: rief_an1002@yahoo.co.id
}

\begin{abstract}
Investigation of fuel element thermal-hydraulic characteristic is important step related to aspect of fuel bundle reactor design. This paper analyzes of the PWR AP1000 and PWR 1000 MWe Typical of fuel bundle thermal-hydraulic using RELAP5 code. Choosing PWR AP 1000 and PWR 1000 MWe Typical because the both of them have almost same power that is 3400 MWth and 3410 MWth but have differences on fuel bundle sum, the high of active core, and rod diameter. On the fuel bundle, there are 17x17 fuel rods that have a radial factor the power varies. Modelling of fuel bundle are divided into 4 channel groups, ie. power factor of 1.396, range power factor of 1.203 to 1.394, power factor of le then 1.198 down and bypass channel. Axially, the channels are divided into 3 zones there are stand-off assembly at the bottom, an active length of the channel and the zone of upper plenum. The active length divided into 10 axial nodes. The goal of this analysis is fuel bundle design validation of PWR AP 1000 and PWR 1000 MWe Typical and get thermal-hydraulic comparison for steady-state condition. The analysis result including cooling floe rate, axial temperature distribution of cladding and cooling temperature, heat flux and pressure drop. In steady condition, the model was verified with the parameter of AP-1000 and PWR 1000 thermal-hydraulic design in which shows a good agreement. Verification results show that the model is made still need refinement, however qualitatively within realistic limits. Further updating of the model will be done to get a better verification results.
\end{abstract}

Keyword: RELAPS, heat flux, reactor, Nuclear, temperature

\section{PENDAHULUAN}

Pembangkit Listrik Tenaga Nuklir (PLTN) merupakan salah satu pembangkit listrik daya thermal yang menggunakan satu atau beberapa reaktor nuklir sebagai sumber panasnya. Prinsip kerja PLTN menggunakan uap bertekanan tinggi untuk memutar turbin dan generator sehingga menghasilkan energi listrik. Sumber panas yang digunakan untuk menghasilkan panas pada PLTN adalah uranium.

PLTN yang masih beroperasi di dunia, 80\% adalah PLTN tipe Reaktor Air Ringan (LWR) yang pertama kali digunakan oleh Amerika. Saat ini, PLTN tipe reaktor air ringan secara garis besar dapat dibedakan menjadi 2 jenis, yaitu Reaktor Air Didih (Boiling Water Reactor; BWR) dan Reaktor Air Tekan (Pressurized Water Reactor; PWR). Perbedaan antara BWR dan PWR terletak pada konstruksi bejana reaktornya dan faktor kondisi air yang digunakan pada reaktor. Reaktor Air Tekan (PWR) lebih banyak digunakan daripada Reaktor Air Didih (BWR) karena desain reaktornya lebih sederhana dan mudah dalam pengawasan dan perawatan sistem.

Di dalam reaktor jenis PWR terdapat peralatan yang berfungsi untuk membangkitkan panas yaitu teras reaktor. Teras reaktor terdiri dari susunan bahan bakar, moderator, dan batang kendali. Pada makalah ini akan dilakukan analisis perbandingan kinerja perangkat bahan bakar PLTN tipe PWR AP1000 dan PWR 1000 MWe Tipikal.

Dipilihnya PWR AP1000 dan PWR 1000 MWe Tipikal sebagai obyek penelitian, karena keduanya mempunyai daya yang hampir sama 3400 MWth dan 3410 MWth tetapi memiliki jumlah perangkat bahan bakar, tinggi teras aktif dan diameter rod berbeda. Perhitungan dilakukan dari segi termal dengan menggunakan program RELAP5 untuk kondisi steady state. Paket program ini dapat digunakan untuk melakukan analisis termohidrolika teras reaktor PWR dan sangat penting sebagai perangkat lunak untuk mengetahui karakteristik termohidrolika teras dan sistem reaktor.

\section{METODOLOGI PENELITIAN}

Diagram alir langkah-langkah penyelesaian masalah diberikan pada Gambar 1. 


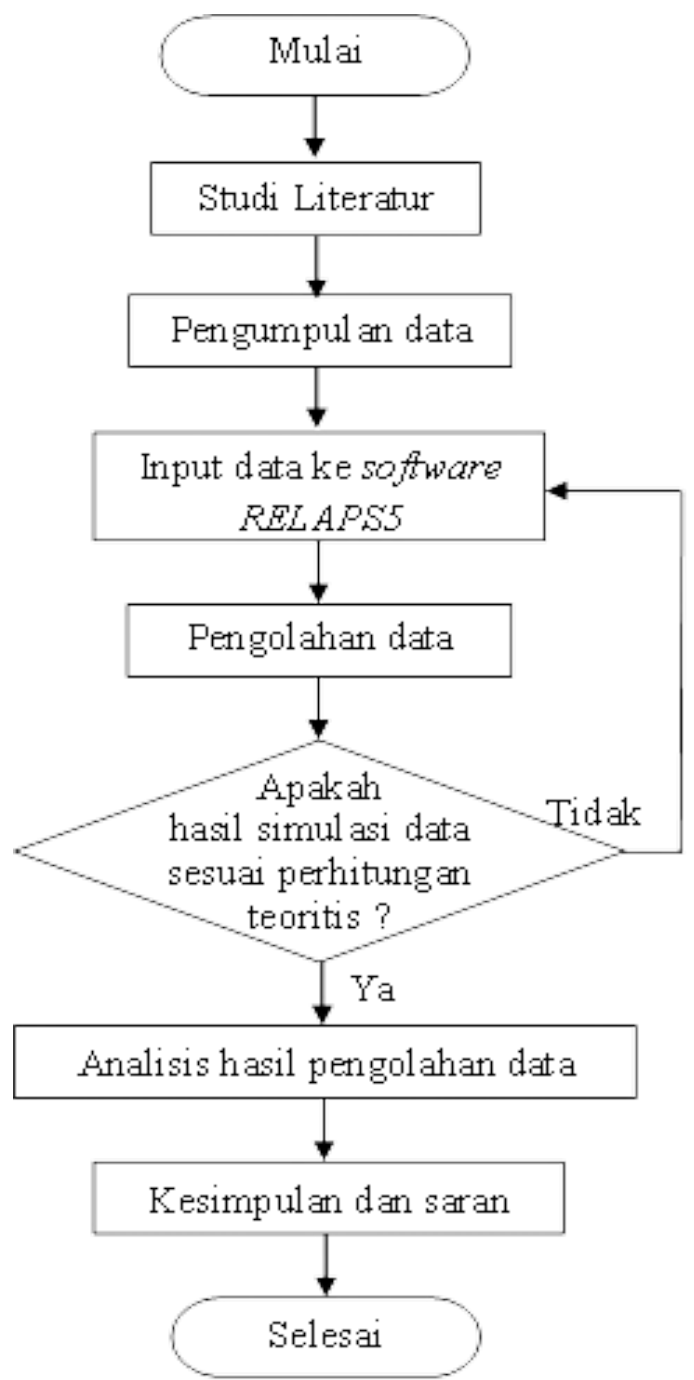

Gambar 1. Diagram alir langkah-langkah penelitian

Seperti diberikan pada Gambar 1 langkah penelitian dimulai dari studi literatur dan dilanjutkan dengan pengumpulan data spesifikasi desain perangkat bahan bakar nuklir PWR AP1000 dan PWR 1000 MWe Tipikal yang akan dijadikan sebagai data pembuatan input program, setelah itu eksekusi program. Program yang digunakan adalah paket program Relap5. Dalam pembuatan input program dimasukan beberapa parameter request untuk mendapatkan distribusi temperatur aksial kelongsong, temperatur pendingin, heat flux dan fraksi void. Apabila hasil eksekusi program tidak sesuai dengan hasil perhitungan teoritis, maka diulangi lagi pembuatan input program. Setelah hasil eksekusi program dan perhitungan teoritis sesuai, maka langkah selanjutnya adalah dilakukan analisis terhadap hasil pengolahan data sehingga mendapatkan suatu kesimpulan sesuai dengan yang diharapkan.

\section{DESKRIPSI PERANGKAT BAHAN BAKAR}

PWR AP-1000 dan PWR 1000 MWe Tipikal memiliki susunan matriks rod bahan bakar yang sama yaitu 17x17 dan satu perangkat terdiri dari 264 rod bahan bakar tetapi keduanya mempunyai perbedaaan ukuran diameter. PWR AP-1000 memiliki diameter 0,95 cm dan PWR 1000 MWe Tipikal berdiameter 0,914 cm.

Pada susunan perangkat bahan bakar terdapat ceramic pellets dengan perkayaan rendah uranium dioxide $\left(\mathrm{UO}_{2}\right)$. Pellets tersebut dimuatkan pad tabung Zirlo, yang mana batang ini ditutup dengan seal-welded di kedua ujungnya. Zirlo merupakan advanced zirconium berbasis alloy. 
Gambar 2 dan 3 menunjukkan satu perangkat bahan bakar pada PWR AP1000 dan data spesifikasi desain teras PWR AP-1000 dan PWR 1000 MWe Tipikal diberikan pada Tabel 1 [1].

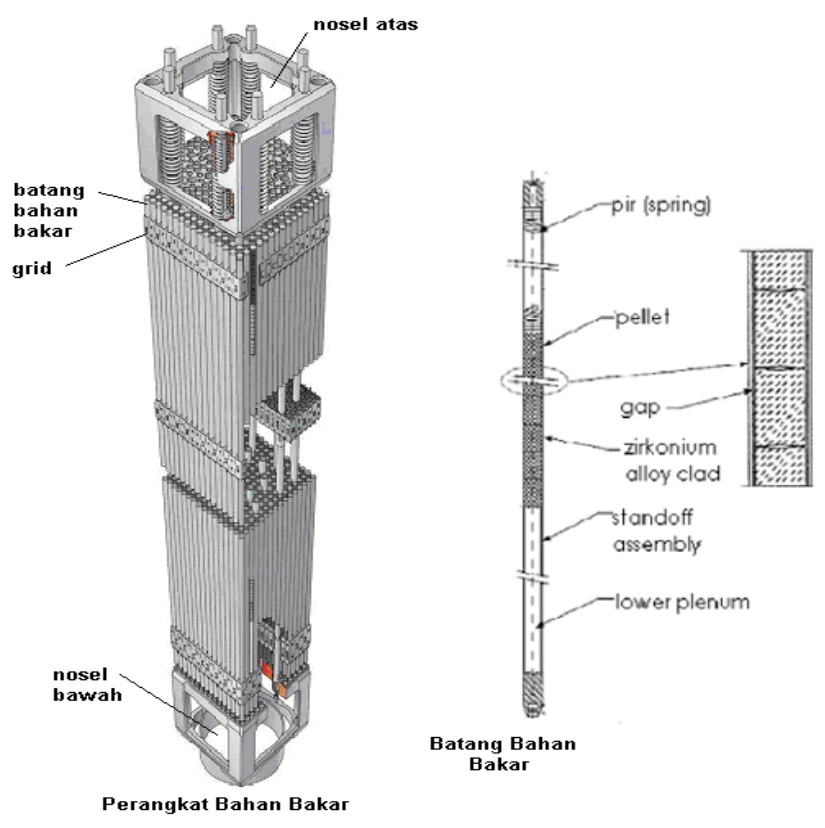

Gambar 2. Perangkat dan batang bahan bakar

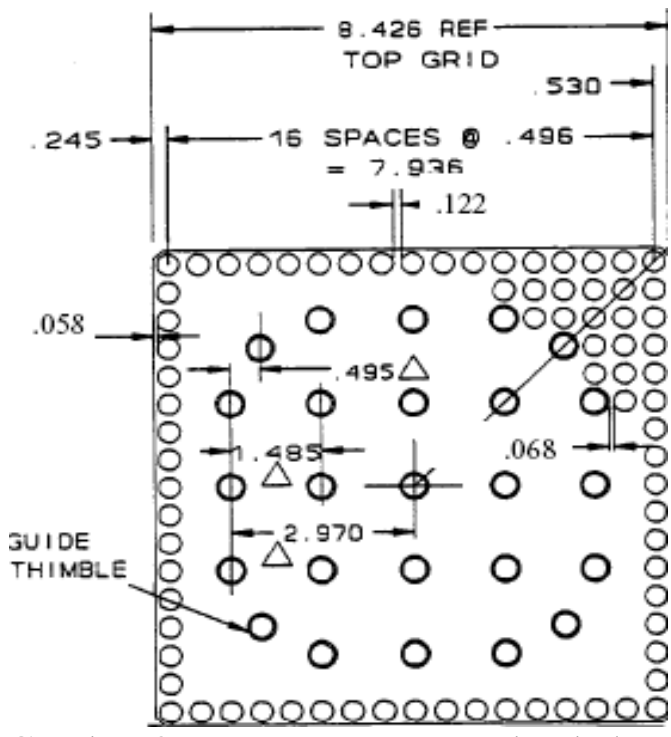

Gambar 3. Penampang perangkat bahan bakar

Tabel 1. Data spesifikasi desain teras PWR AP 1000 dan PWR 1000 Tipikal

\begin{tabular}{clcc}
\hline No. & Parameter & \multicolumn{2}{c}{ Keterangan } \\
\hline 1. & Tipe PLTN & AP 1000 & PWR 1000 Tipikal \\
2. & Desainer/Vendor & Westinghouse & Westinghouse \\
3. & Daya termal & 3400 & 3411 \\
4. & Laju alir efektif $(\mathrm{kg} / \mathrm{jam})$ & $48,44 \times 10^{6}$ & $59,053 \times 10^{6}$ \\
5. & Tekanan operasi $(\mathrm{MPa})$ & 15,00 & $15,15,17$ \\
6. & Suhu inlet pendingin $\left({ }^{\circ} \mathrm{C}\right)$ & 279,44 & 292,00 \\
7. & Suhu outlet pendingin $\left({ }^{\circ} \mathrm{C}\right)$ & 324,66 & 328,30 \\
8. & Diameter teras $(\mathrm{cm})$ & 304,04 & 337,06 \\
9. & Tinggi teras aktif $(\mathrm{cm})$ & 426,72 & 365,76 \\
10. & Jumlah perangkat bahan bakar & 157 & 193 \\
11. & Tipe perangkat bahan bakar & $17 \times 17$ & $17 \times 17$ \\
12. & Ukuran perangkat bahan bakar $(\mathrm{cm} \times \mathrm{cm})$ & $21,40 \times 21,40$ & $21,40 \times 21,40$ \\
13. & Jumlah rod/perangkat & 264 & 264 \\
14. & Jarak antar pusat rod & 1,26 & 1,26 \\
15. & Diamater rod $(\mathrm{cm})$ & 0,950 & 0,914 \\
16. & Diameter pellet $(\mathrm{cm})$ & 0,819 & 0,874 \\
17. & Fluks panas rata-rata $\left(\mathrm{kW} / \mathrm{m}^{2}\right)$ & 628,71 & 622,09 \\
18. & Fluks panas maksimum $\left(\mathrm{kW} / \mathrm{m}^{2}\right)$ & 1634,71 & 1555,21 \\
\hline
\end{tabular}

\section{PEMODELAN PERANGKAT BAHAN BAKAR}

Dalam pemodelan satu perangkat bahan bakar, dapat dibagi menjadi beberapa kelompok kanal yang tiap kelompok memuat kanal volume pendingin dan struktur panas (pembangkit panas). Dalam hal ini setiap posisi batang bahan bakar memiliki faktor pembangkitan daya radial yang berbeda menyebar pada 17x17 batang bahan bakar. Oleh karena itu berdasarkan data dari faktor pembangkitan daya radial, pemodelan ini membagi menjadi 4 kanal berdasarkan pengelompokan dari faktor daya yaitu daya terbesar (kanal terpanas), daya menengah, daya rendah dan kanal 
by-pass. Kanal I mewakili posisi kanal dengan faktor daya terbesar yaitu 1,396 (Posisi H9, I10), kanal II mewakili posisi kanal pada rentang faktor daya 1,203 sampai 1,394 (Posisi B15, G9), kanal III mewakili posisi lain yang lebih kecil dari 1,198 (posisi O16), kanal IV adalah lintasan aliran yang disimulasikan bilamana terjadi aliran by-pass (aliran pendingin yang tidak melalui bagian di mana terjadi transfer panas) [2].

Secara aksial, setiap kanal ditetapkan menjadi 10 node, di mana pembagian tersebut sudah cukup untuk merepresentasikan kurva pola distribusi daya aksial, sedangkan model pada stand-off dan plenum atas hanya dibagi menjadi 4 node. Jadi secara keseluruhan, model perangkat ini memiliki 2 tmdpvol, 1 tmdjunc, 13 volume, 1 single volume dan 2 model branch. Gambar 4 menunjukkan gambar nodalisasi pada model perangkat. Tabel 2 menyajikan data kompilasi untuk mendukung dalam penyusunan input deck, Tabel ini disusun kembali berdasarkan data referensi yang tersedia.

Tabel 2. Data kompilasi untuk penyusunan input deck

\begin{tabular}{lrrrr}
\hline Parameter & Kanal I & Kanal II & Kanal III & Kanal IV \\
\hline Panj. aktif bahan bakar (m) & 4,267200 & 4,2672 & 4,2672 & 0 \\
Panj. Stand-off assembly (m) & 0,143129 & 0,143129 & 0,143129 & 0,143129 \\
Panj. Plenum atas (m) & 0,164465 & 0,164465 & 0,164465 & 0,164465 \\
Panj./Node St. assembly (m) & 0,035782 & 0,035782 & 0,035782 & 0,035782 \\
Panj./Node kanal aktif (m) & 0,426720 & 0,426720 & 0,426720 & 0,426720 \\
Panj./Node plenum atas (m) & 0,041116 & 0,041116 & 0,041116 & 0,041116 \\
Volume-angle ( ${ }^{\circ}$ ) & 90 & 90 & 90 & 90 \\
Diameter hidrolik (m) & 0,011179 & 0,011179 & 0,011179 & - \\
Luas aliran kanal (m $\left.{ }^{2}\right)$ & 0,0001756 & 0,0540848 & 0,0093068 & 0,000000001 \\
Laju aliran pendingin (kg/s) & 1,16 & 444,66 & 30,74 & 0,00001 \\
Panj. Plenum atas (m) & 4,262700 & 4,2627 & 4,2627 & 0 \\
Kekerasan permukaan (m) & $1,5 \mathrm{E}-5$ & $1,5 \mathrm{E}-5$ & $1,5 \mathrm{E}-5$ & $1,5 \mathrm{E}-5$ \\
Temperatur inlet pendingin (K) & 552,4000 & 552,40 & 552,40 & 552,40 \\
Tekanan inlet pendingin (MPa) & $148,80+5$ & $148,80+5$ & $148,80+5$ & $148,80+5$ \\
Jumlah batang bahan bakar (-) & 4 & 154 & 106 & 0 \\
Faktor daya radial (-) & 1,3960 & 1,227 & 1,188 & 0 \\
\hline
\end{tabular}

\section{DESKRIPSI RELAP 5}

RELAP5 adalah paket program komputer termohidrolika satu dimensi yang telah digunakan secara luas untuk melakukan simulasi steady-state maupun transien pada suatu sistem termal dan pendingin air ringan pada reaktor nuklir. Paket ini dikembangkan oleh U.S. Nuclear Regulatory Commission (US NRC). Versi Scdap dari Innovative Software System, Idaho Falls dilengkapi dengan paket analisis kecelakaaan teras terparah [3].

Paket program ini menggunakan model node dan junction multi-dimensional untuk menghitung keseluruhan perilaku termohidrolika sistem pendingin. Model yang digunakan merupakan sistem hidrodinamika nonequilibrium dan nonhomogenous fluida dua-fasa termasuk untuk gas-gas tak terkondensasi, transfer panas secara konveksi, konduksi satu dimensi pada struktur sistem, kinetika reaktor, sistem kontrol dan logika trip. Paket program juga mengandung model komponen sistem pada reaktor pendingin air ringan (Light Water Reactor, LWR) seperti pompa, katup, turbin, separator dan sebagainya [4].

\section{HASIL DAN PEMBAHASAN}

Penelitian penggunaan program komputer untuk menganalisa kinerja perangkat bahan bakar diberikan pada grafik yang dinyatakan pada Gambar 5 sampai dengan 10. Penelitian dilakukan terhadap perangkat bahan bakar PWR AP1000 MWe dan PWR 1000 MWe Tipikal. Hasil yang diperoleh antara lain distribusi laju aliran pendingin sepanjang kanal aktif, distribusi temperatur 
keluar pendingin dan kelongsong sepanjang kanal serta distribusi tekanan aliran dan fluks panas sepanjang kanal.

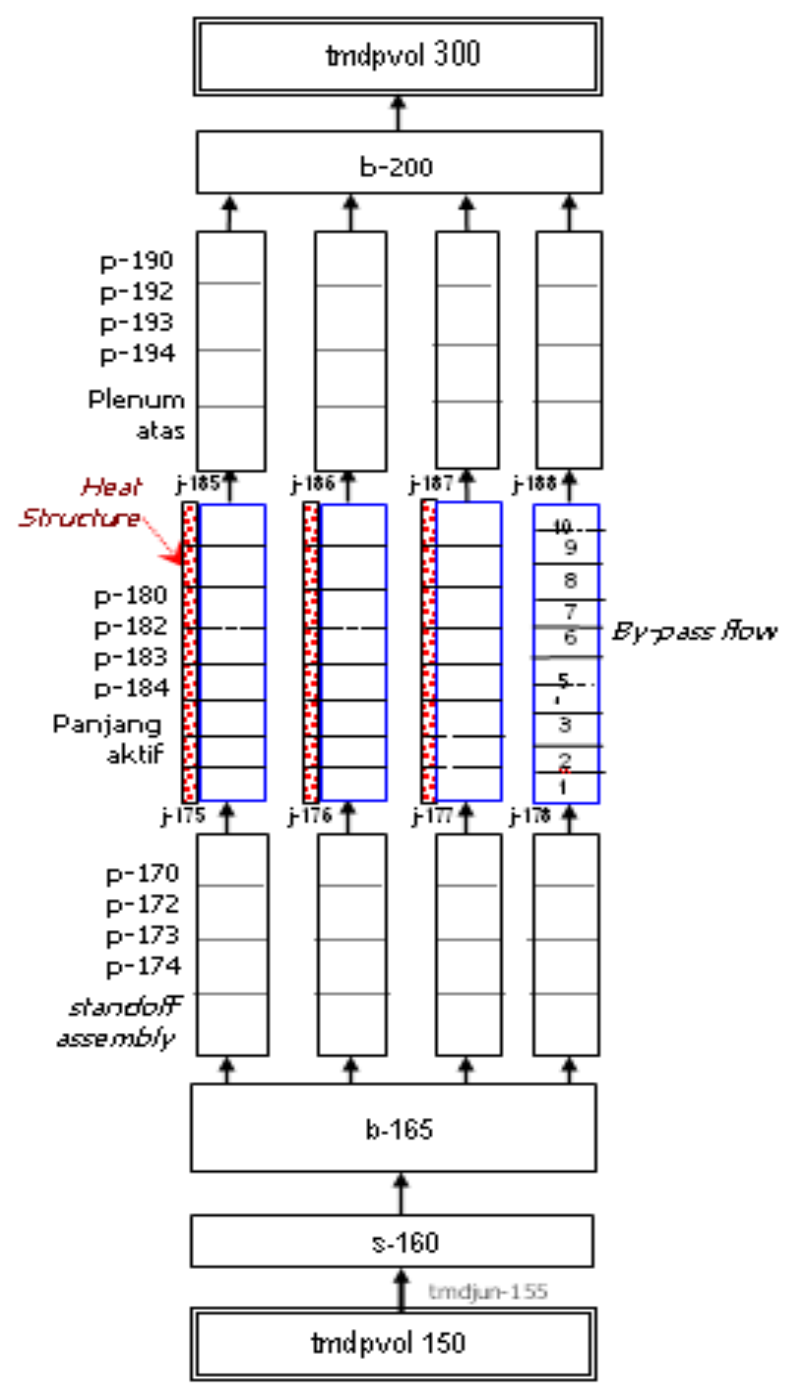

Gambar 4. Nodalisasi model perangkat bahan bakar

Pada dasarnya proses running program RELAP5 adalah untuk mendapatkan kurva-kurva pencapaian steady-state. Dalam hal ini tidak membutuhkan waktu yang lama, kualifikasi steadystate yang stabil telah ditetapkan sampai 200 detik dimana perolehan kondisi steady-state sangat memadai [5].

Pencapaian kondisi stabil parameter laju pendingin PWR AP 1000 ditunjukan pada Gambar 5. Besarnya laju aliran pendingin ditiap kanal ini dipengaruhi oleh luas aliran enthalpy pendingin yang mengalir. Laju aliran pada masing-masing kanal adalah $1.16 \mathrm{~kg} / \mathrm{s}$ (kanal I), $47.58 \mathrm{~kg} / \mathrm{s}$ (kanal II), 32.73 (kanal III dan $0.0 \mathrm{~kg} / \mathrm{s}$ (Kanal IV). Kanal IV merupakan model untuk aliran by- pass yang dalam analisis ini luas alirannya di-inputkan sama dengan nol.

Pencapaian kondisi stabil parameter laju aliran pendingin PWR 1000 MWe Tipikal ditunjukan pada Gambar 6 dengan laju aliran pendingin sebagai fungsi interval waktu antara 0 sampai dengan 200 detik. Grafik ini menunjukan keadaan steady-state untuk tiap-tiap kanal. Terdapat sedikit penurunan grafik pada kanal II, namun hal itu masih menunjukan bahwa hasil yang didapat relevan. Laju aliran pendingin masing-masing adalah $1.36 \mathrm{~kg} / \mathrm{s}$ untuk kanal I, $47.56 \mathrm{~kg} / \mathrm{s}$ untuk kanal II, 33.99 kg/s untuk kanal III dan 0.0 untuk kanal IV. Kanal IV merupakan kanal bypass. 


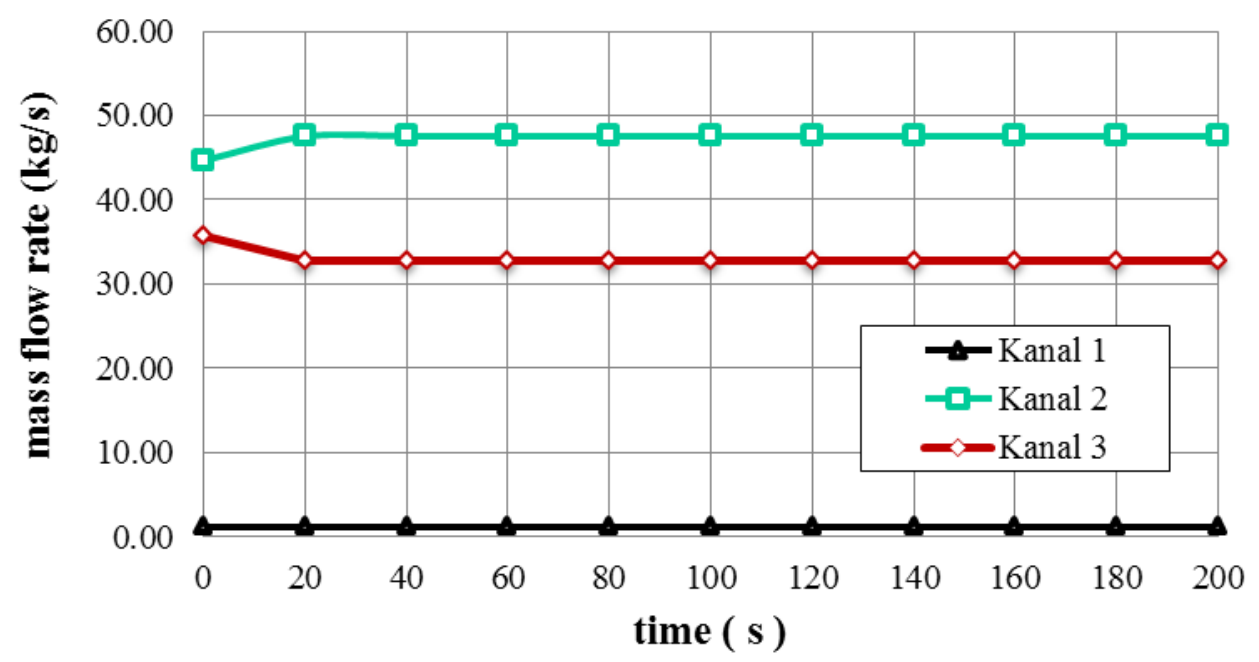

Gambar 5. Kurva pencapaian steady-state laju aliran pendingin sepanjang kanal aktif PWR AP 1000

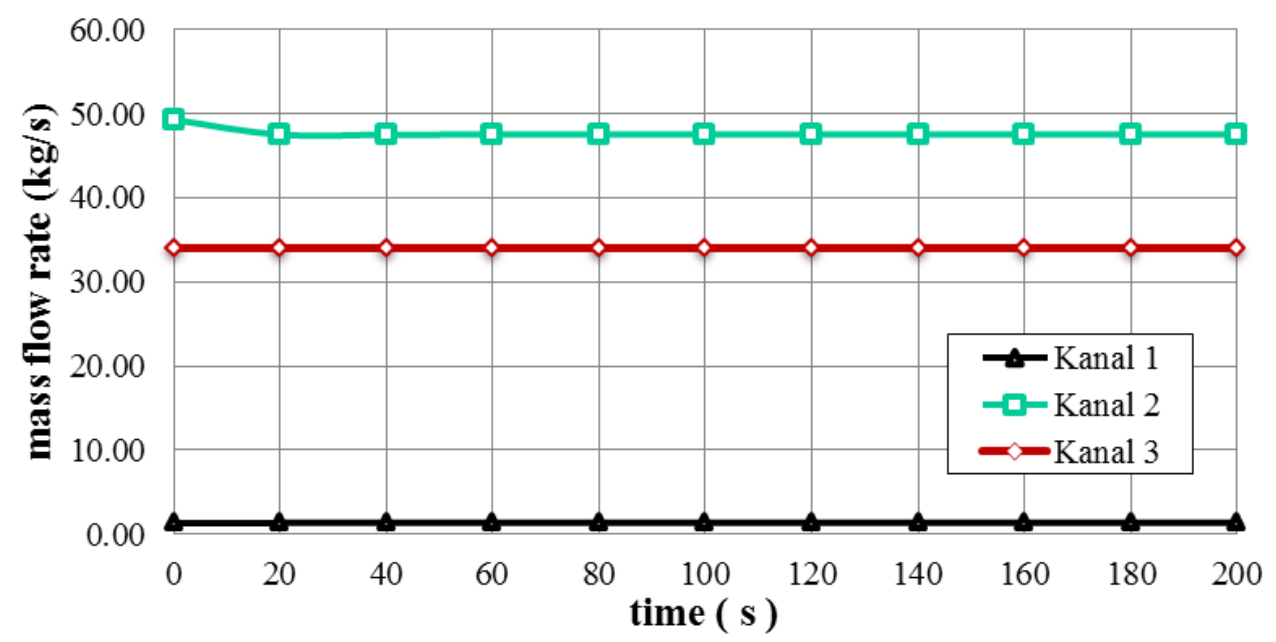

Gambar 6. Kurva pencapaian steady-state laju aliran pendingin sepanjang kanal aktif PWR 1000 Mwe Tipikal

Dari hasil grafik laju aliran pendingin untuk masing-masing tipe perangkat bahan bakar, kedua grafik tersebut menunjukan keadaan steady-state. Hal itu sangat relevan untuk pemodelan yang dilakukan. Karena untuk tiap-tiap perangkat perbedaan persentasenya tidak terlalu signifikan. Sehingga dapat disimpulkan untuk laju aliran pendinginan untuk perangkat bahan bakar tipe PWR AP 1000 dan PWR 1000 MWe Tipikal dapat diterima.

Parameter berikutnya adalah temperatur pendingin dan temperatur kelongsong untuk tiaptiap perangkat bahan bakar tipe PWR AP 1000 dan PWR 1000 MWe Tipikal. Untuk temperatur pendingin dan temperatur kelongsong PWR AP 1000 disampaikan pada Gambar 7 dimana temperatur masuk pendingin kanal-I ini adalah data input yang sekaligus merupakan temperatur masuk ke teras reaktor. Oleh karena itu kurva di temperatur ini (552.40) tidak berubah fungsi. Adapun temperatur keluar perangkat bahan bakar yang dihitung oleh RELAP5 bervariasi untuk masing-masing kanal. Hasilnya adalah $612.34 \mathrm{~K}$ (kanal I), 605.78 K (Kanal II) dan 601.52 (Kanal III). Temperatur ini masih di atas temperatur pendingin rerata keluar teras dari data desain (597.67 K). sedangkan untuk penelusuran temperatur kelongsong, dalam hal ini dipilih kanal terpanas (Kanal-I node no-5) dimana pada lokasi ini faktor daya radial dan aksial adalah maksimum. Kondisi steady-state diperoleh pada temperatur $631.56 \mathrm{~K}$. 
Parameter Temperatur pendingin dan temperatur kelongsong untuk PWR 1000 MWe Tipikal disampaikan pada Gambar 8 untuk temperatur masuk pendingin kanal-I tersebut merupakan data input masuk ke teras reaktor adalah $565.6 \mathrm{~K}$. dan untuk temperatur keluar perangkat masingmasing 613.27 K (Kanal I), 582.54 K (Kanal II) dan 613.22 K (kanal III). Untuk temperatur kelongsong saat steady-state adalah 748.98K.

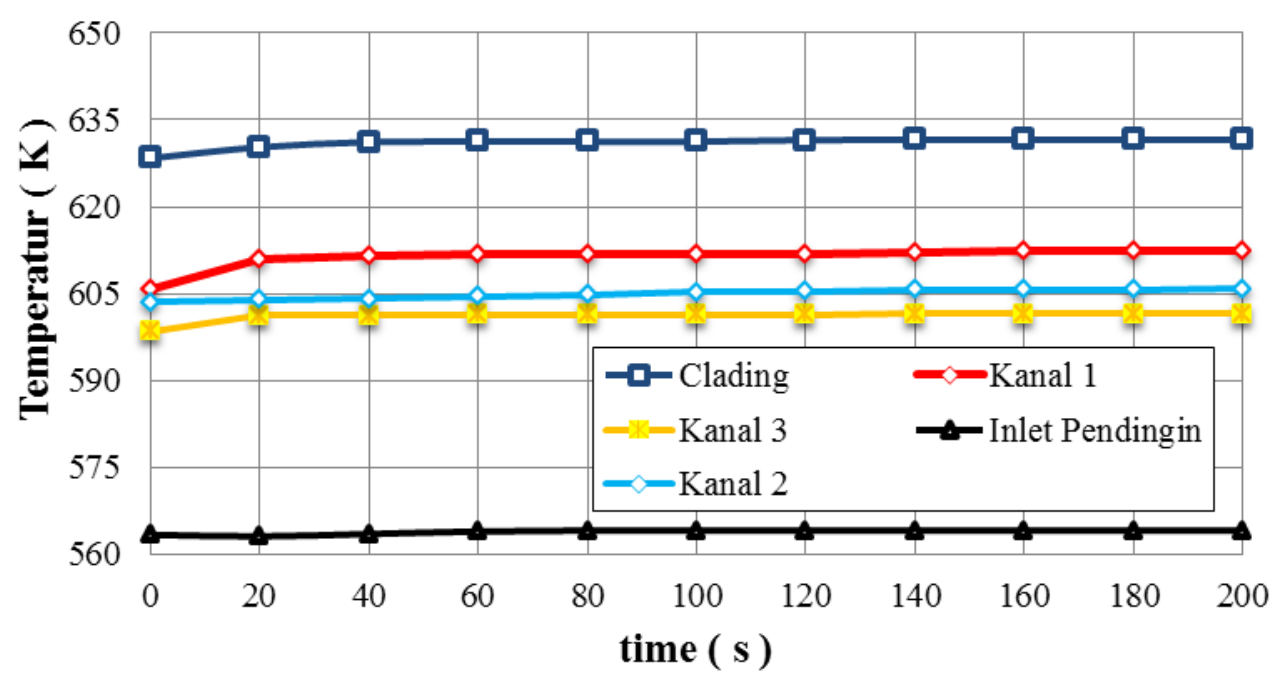

Gambar 7. Kurva steady-state temperatur keluar pendingin dan kelongsong sepanjang kanal PWR AP 1000

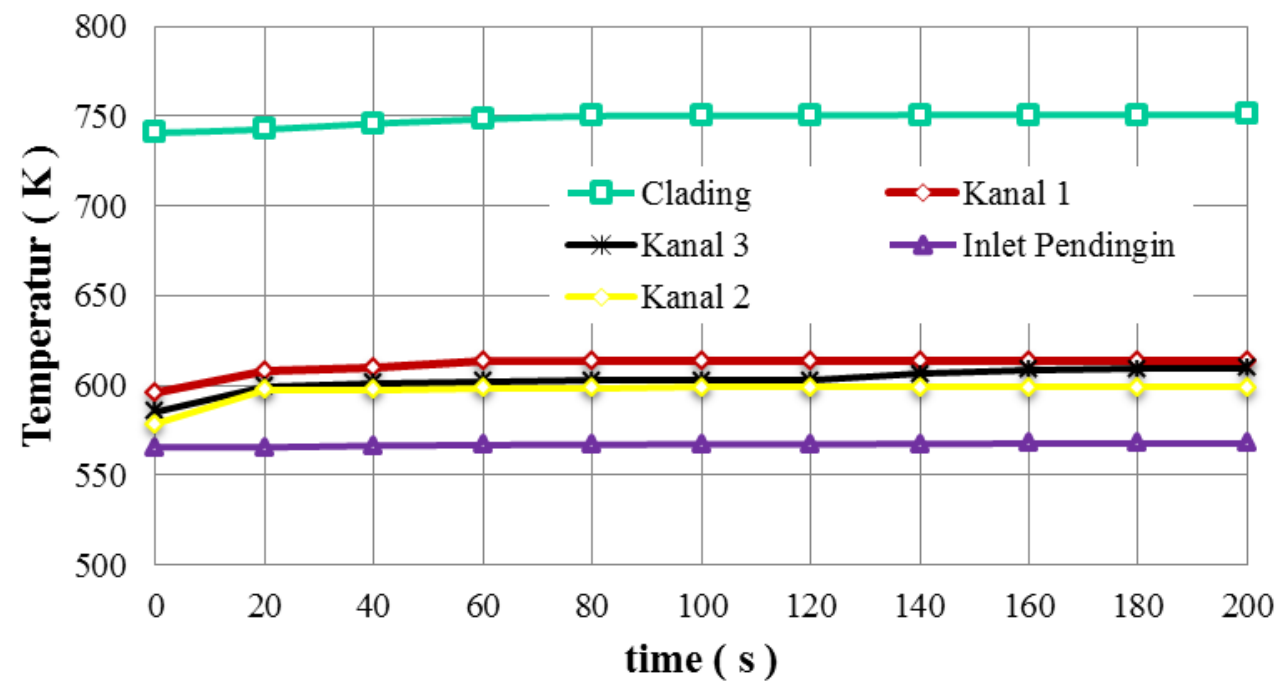

Gambar 8. Kurva steady-state temperatur keluar pendingin dan kelongsong sepanjang kanal PWR 1000 Mwe Tipikal

Dari kedua grafik temperatur keluar pendingin dan kelongsong ini masing-masing grafik cenderung menunjukan kondisi Steady-state. Dan hal ini tentu menjelaskan bahwa kedua grafik tersebut dapat di terima dan relevan untuk pemodelan.

Pencapaian kondisi stabil parameter tekanan masuk, tekanan keluar dan heat flux di tunjukan pada Gambar 9 dan 10. Dimana pada gambar tersebut menampilkan kurva heat flux yang terjadi pada lokasi terpanas (kanal I node no-5) perangkat bahan bakar dari pemodelan. Untuk grafik tekanan masuk, tekanan keluar serta heat flux PWR AP1000 ditunjukan pada Gambar 9. Heat flux untuk AP 1000 adalah $1634000\left(\mathrm{w} / \mathrm{m}^{2}\right.$ ). Pada rentang waktu 100 hingga 160 detik terjadi kenaikan grafik yang cukup signifikan, hal ini disebabkan adanya perubahan fasa dari cair menjadi 
uap sehingga nilai heat flux meningkat cukup tinggi. Penurunan tekanan yang terjadi pada PWR AP 1000 adalah $98000 \mathrm{~Pa}$.

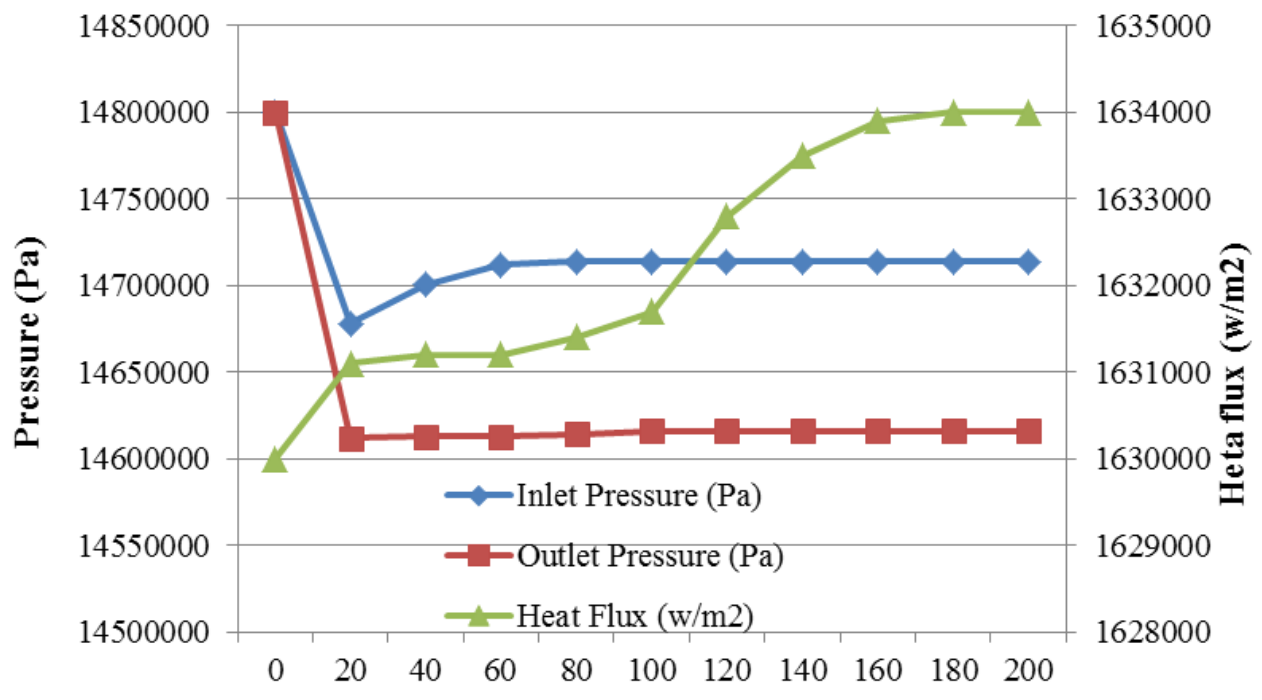

Time (s)

Gambar 9. Kurva steady-state tekanan aliran dan heat flux sepanjang kanal PWR AP1000 MWe

Tekanan aliran masuk serta keluar dan heat flux untuk tipe perangkat bahan bakar PWR1000 MWe Tipikal di tunjukan pada Gambar 10. dimana untuk hasil tekanan masuk serta tekanan keluar aliran grafik menunjukan keadaan steady-state. Hal ini dapat diterima sebagai pemodelan. Untuk hasil heat flux terpanas perangkat bahan bakar PWR ini didapat hasil $1554000\left(\mathrm{w} / \mathrm{m}^{2}\right)$. Sedangkan untuk hasil penurunan tekanan yang terjadi pada perangkat ini hasilnya adalah $94800 \mathrm{~Pa}$.

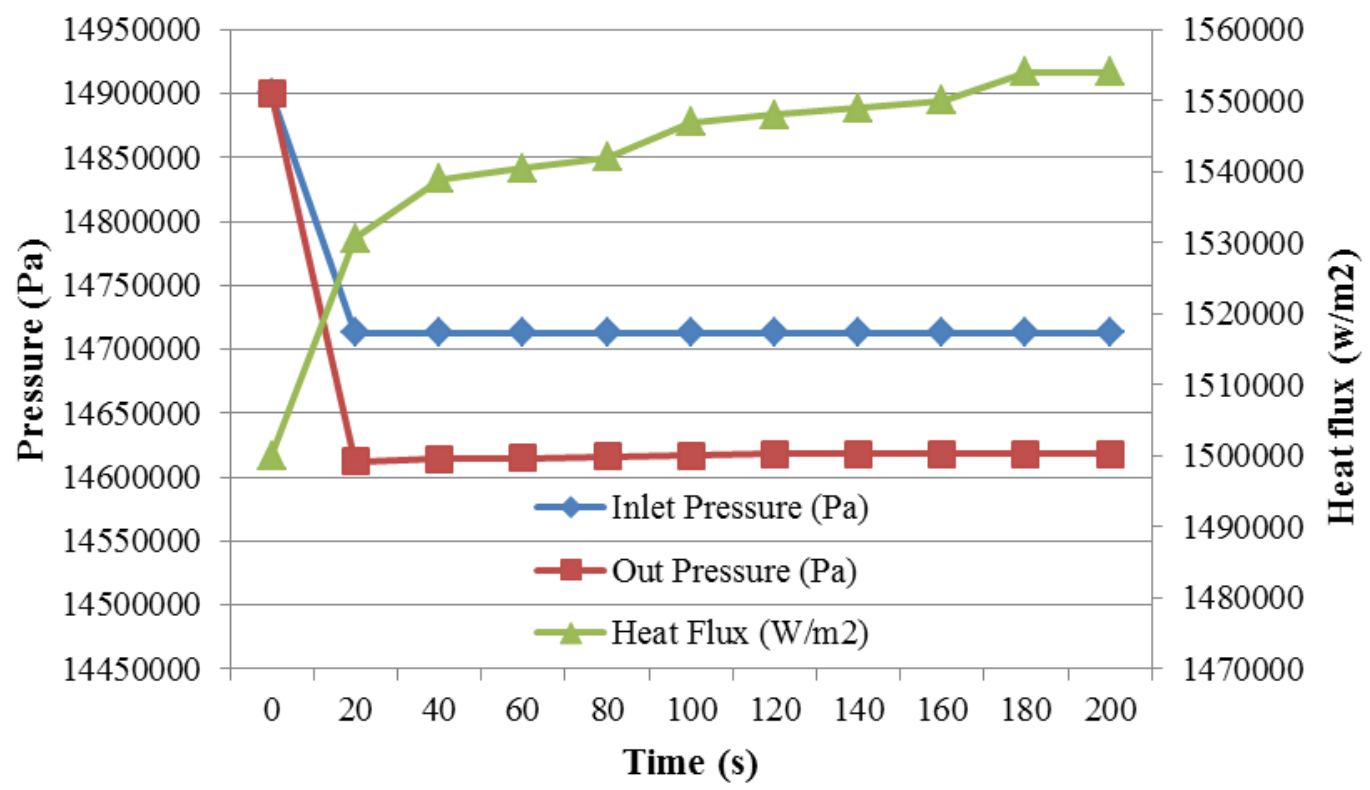

Gambar 10. Kurva steady-state tekanan aliran dan heat flux sepanjang kanal PWR 1000 MWe Tipikal

Kedua grafik tekanan aliran dan heat flux menunjukan keadaan steady-state. Hal ini menunjukan bahwa kedua data tersebut baik dilakukan untuk dijadikan pemodelan karena perbedaan persentase tekanan untuk keduanya tidak terlalu signifikan. 


\section{KESIMPULAN}

Hasil perhitungan termohidrolika perangkat bahan bakar PWR AP-1000 dan PWR 1000 Mwe Tipikal menggunakan paket program RELAP5 yang meliputi distribusi heat flux, temperatur kelongsong, dan pendingin sepanjang kanal bahan bakar aktif berhasil dilakukan untuk validasi model perangkat pada RELAP5 dan tidak terdapat perbedaan yang signifikan terhadap data desain yang diacu. Dengan demikian telah diperoleh karakteristika termal teras PWR AP -1000 dan PWR 1000 MWe Tipikal hasil pemodelan yang dihitung dengan menggunakan paket program RELAP5.

\section{DAFTAR PUSTAKA}

[1]. Ralph, A. Nelson, et al Phenomogical Thermal-hydraulic model of Hot Rod bundel experiencing and optimization methodology for closure development, Reflood completion report, DOE, USA, 1996

[2]. Kazimi, M.S and Todreas, N.E., Nuclear System I, Hemisphere Publishing Corporation, New York, 1991.

[3]. Anonim, RELAP5 Code Development Team, RELAP5/MOD3. Code Manual User Guide and Input Requirements, NUREG/CR-5535-V2. Idaho National Engineering Laboratory, Washington DC.1995.

[4]. Patrícia et.al” Sensitivity Analysis of the RELAP5 Nodalization to IPR-R1 TRIGA Research Reactor', International Conference on Mathematics and Computational Methods Applied to Nuclear Science and Engineering (M\&C 2011) Rio de Janeiro, RJ, Brazil, May 8-12, 2011.

[5]. Sukmanto, Dibyo. dkk., Validasi Pemodelan Test-Section Queen Menggunakan Relap5, Prosiding Seminar Nasional ke-16 Teknologi dan Keselamatan PLTN serta FasilitasNuklir, PTRKN - ITS, Surabaya, 2010. 